\title{
Evaluation of the community pharmacists' performance in the screening of non-steroidal anti-inflammatory drugs risks in Saudi Arabia
}

Azizah M. Malebari, MSc, PhD, Ahdab N. Khayyat, MSc, PhD, Ruba A. Mahdali, PharmD, Jumana S. Alamoudi, PharmD, Bushra Y. Alsayed, PharmD, Samar A. Alrasheed, PharmD.

\begin{abstract}

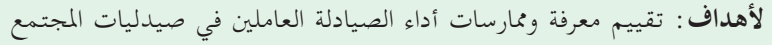

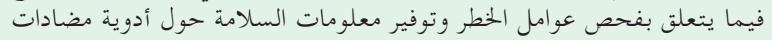

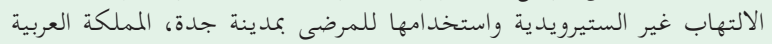
السعودية.

المنهجية : أُجريت دراسة مستعرضة بالإعتماد على الإستبيان الذاتي خلال الفترة

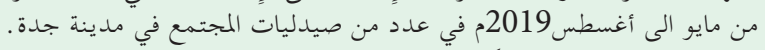

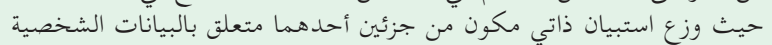

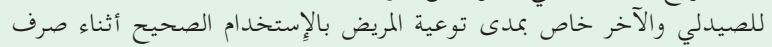

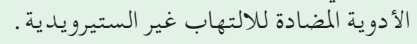

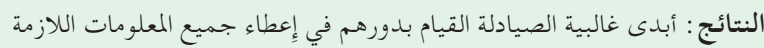

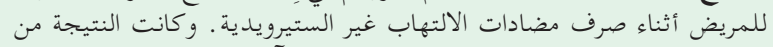

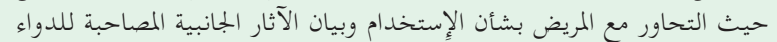

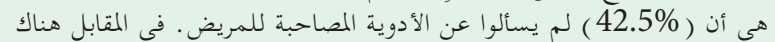

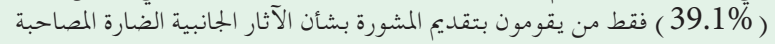

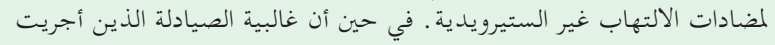

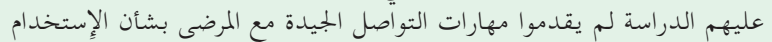

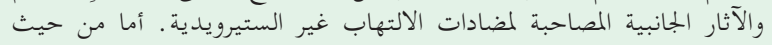

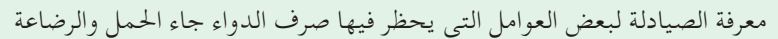

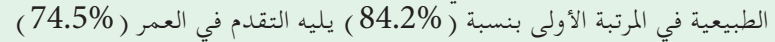

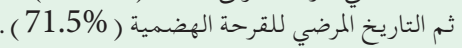

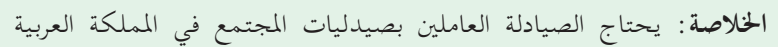

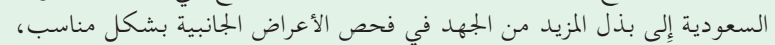

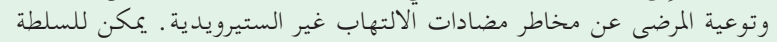

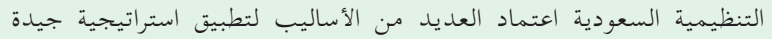

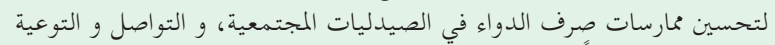

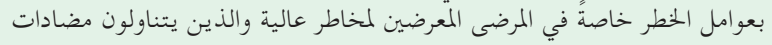

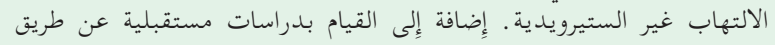

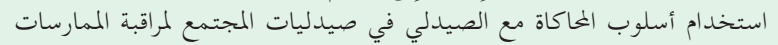
الصحيحة المطلوبة منه . أسلو ألمات
\end{abstract}

Objectives: To assess community pharmacists' knowledge and practices regarding screening risk factors and providing safety information about the use of nonsteroidal anti-inflammatory drugs (NSAIDs) to patients.

Methods: Cross-sectional and a self-administered questionnaire-based study was conducted over a 4-month period (May-August 2019) with selected community pharmacies in Jeddah, Saudi Arabia. The questionnaire composed of demographic data and the pharmacist's role in supplying NSAIDs.

Results: The majority of participating community pharmacists dispense NSAIDs. However, many did not apply relevantly good communication skills such as seeking information about concomitant drugs (42.5\%) or providing advice on managing any adverse side effects of taking NSAIDs (39.1\%). Most of the community pharmacists also did not provide relevantly good communication about risk factors. The most common screening risk factors mentioned were a history of pregnancy and breastfeeding $(84.2 \%)$ followed by being at an older age $(74.5 \%)$ or a history of a gastrointestinal ulcer $(71.5 \%)$.

Conclusion: Community pharmacists in Saudi Arabia need to appropriately screen their patients for adverse drug reactions and effectively communicate the risks of using NSAIDs. The Saudi Regulatory Authority could endorse several approaches to apply a good strategy for improving the dispensing practices in community pharmacies, communication and awareness of risk factors especially in high-risk patients who are taking NSAIDs.

Keywords: non-steroidal anti-inflammatory drugs, NSAIDs, community pharmacists, counseling practice, adverse drug reactions

Saudi Med J 2020; Vol. 41 (8): 849-857 doi: 10.15537/smj.2020.8.25221

From the Department of Pharmaceutical Chemistry (Malebari, Khayyat), College of Pharmacy, King Abdulaziz University; and from the College of Pharmacy (Mahdali, Alamoudi, Alsayed, Alrasheed), King Abdulaziz University, Jeddah, Kingdom of Saudi Arabia.

Received 2nd May 2020. Accepted 12th July 2020.

Address correspondence and reprint request to: Dr. Azizah M. Malebari, Department of Pharmaceutical Chemistry, College of Pharmacy, King Abdulaziz University, Jeddah, Kingdom of Saudi Arabia. E-mail: amelibary@kau.edu.sa

ORCID ID: https://orcid.org/0000-0003-4178-0341 
A nalgesics, such as non-steroidal anti-inflammatory drugs (NSAIDs) and acetaminophen (APAP), are the most common over-the-counter (OTC) drugs in the world used to treat fever, pain, and decrease inflammation. ${ }^{1,2}$ Non-steroidal anti-inflammatory drugs act by blocking the cyclo-oxygenase (COX) enzyme, which causes direct inhibition of the biosynthesis of thromboxane and prostaglandins from arachidonic acid. They are used for treating mild-to-moderate pain that arises from a variety of conditions such as osteoarthritis, rheumatoid arthritis, menstruation, headaches, or toothaches.

In Saudi Arabia, analgesics were one of the top 10 most used drugs between 2010 and 2015 and the NSAIDs class represented $67 \%$ of use. ${ }^{3}$ Many studies in Saudi Arabia found that the majority of people use the NSAIDs ibuprofen and diclofenac to treat headaches, colds, cramps, and fever. ${ }^{2,4}$ As well as, a recent study in Saudi Arabia (2019) found that around one-half of the participants in the study practised self-medication with these drugs primarily for pain management. ${ }^{5}$

Non-steroidal anti-inflammatory drugs are classified according to their preference for specific enzymes (example, COX-1 or COX-2). The non-selective NSAIDs like aspirin are more likely to cause adverse gastrointestinal (GI) effects while those that target COX-2 like celecoxib have a higher risk of negative cardiovascular effects. ${ }^{6}$ Although NSAIDs relieve pain, they can also cause severe side effects such as heartburn, stomach ulcers, and a tendency towards bleeding, liver or kidney problems, or high blood pressure. ${ }^{6}$

There are so many critical information that patients should know regarding the use of NSAIDs, such as they should not be taken around the time of any heart surgery. Non-steroidal anti-inflammatory drugs elevate the probability of developing an ulcer or internal bleeding in patients with a history of these issues. Advanced age, history of smoking, advanced liver disease, or chronic users of NSAIDs are more susceptible to these adverse effects. Pregnancy, asthma, and hypertension should be also taken into consideration before using NSAIDs. ${ }^{7}$

It has been reported that more than 16,500 people die annually from NSAID-related GI complications. ${ }^{8}$ Moreover, a recent study found that the most common drugs related to a need for hospital admission were NSAIDs. ${ }^{9} \quad$ Non-steroidal anti-inflammatory drugs

Disclosure. Authors have no conflict of interests, and the work was not supported or funded by any drug company. increased the possibility of developing adverse GI events 2.5 times. ${ }^{10}$ In addition, they can cause bronchospasms so patients with asthma may have more acute symptoms after taking NSAIDs. In addition, NSAIDs co-prescribed with corticosteroids increases bleeding risks 12-fold, which is more likely to be fatal. ${ }^{11}$ Moreover, patient knowledge and recognition of the risks of NSAIDs are inadequate and cause for concern. Many studies found that there is an overuse of NSAIDs medication among people and that the majority of them did not receive any counseling or information from health care providers about the appropriate use of NSAIDs. ${ }^{12,13}$

In Saudi Arabia, a great responsibility relies on pharmacists to improve the prescribing practice of NSAID medications. The community pharmacy is the main source for patients to seek pain relief, as NSAIDS may be dispensed without a prescription. A recent published article (2018) showed 24395 authorized pharmacists and pharmacy technicians in Saudi Arabia as of March 2017. ${ }^{14}$ They are distributed across the kingdom's regions. The highest percentage in Riyadh region followed by Makkah region as $25 \%$ of registered pharmacist with the average age of 38 years. ${ }^{14}$ The community pharmacists represent the highest percentage $(34.5 \%)$ across others pharmacy sectors. This study focus on assessing the self-reported practices regarding the performance of community pharmacists in NSAIDs dispensing, risk factors evaluation and offering appropriate advice and information about side effects and their management.

Methods. A cross-sectional study including community pharmacists was carried out in Jeddah, Saudi Arabia between May 2019 and August 2019. The study population included only pharmacists who are working in community pharmacies. There are 1182 pharmacies licensed by the Saudi Food and Drug Administration (Saudi FDA) in Jeddah, Saudi Arabia and this list was obtained from the annual statistical book from the Ministry of Health. ${ }^{15}$ Ethical approval for this study protocol was attained from the Ethics Committee for Human Research, King Abdulaziz University (PH-103-41).

We divided Jeddah, Saudi Arabia by using 5 geographical areas: north, south, west, east, and central. A convenient sample of pharmacies from different areas was selected. Pharmacy students visited pharmacies and asked the pharmacists about their willingness to participate in a study about the pharmacist's role in supplying NSAIDs in community pharmacies. The questions in the survey were adapted from a previous study performed in Thailand. ${ }^{16}$ The questionnaire was 
divided into 2 parts: demographic data and the role of pharmacists in supplying NSAIDs. The second part consisted of 12 sections about the screening risk regarding adverse drug reactions (ADRs). and 8 advice on ADRs management: i) highlights the concomitant drug with NSAIDs, communicating and educating patients about potential side effects, ii) screening patients at risk factors, iii) and giving advices and information to patients using NSAIDs. Choices concerning to the prevalence of pharmacist profession in each question were recorded (as regularly, occasionally, or never). Ten pharmacists tried out this questionnaire and the content validity was subjected to a panel of pharmacist experts. The questionnaire was presented to 390 community pharmacists at their place of work. However, 190 of the community pharmacists either refused to participate in the study or forgot to return the survey back. Therefore, 200 of community pharmacists were willing to engage in the study and complete questionnaires that were

Table 1 - Characteristics of community pharmacist respondents.

\begin{tabular}{|c|c|}
\hline Characteristics & $(\mathrm{N}=200)$ \\
\hline Gender & $\mathrm{n}(\%)$ \\
\hline Female & $9 \quad(4.5)$ \\
\hline Male & $191(95.5)$ \\
\hline \multicolumn{2}{|l|}{ Age } \\
\hline Means $\pm S D$ (years) & $33.8 \pm 7.09$ \\
\hline Min-max & $23-55$ \\
\hline \multicolumn{2}{|l|}{ Educational level } \\
\hline Diploma & $11(5.5)$ \\
\hline Bachelor of Science & $130 \quad(65)$ \\
\hline Doctor of Pharmacy & $56 \quad(28)$ \\
\hline Master of Science & $3(1.5)$ \\
\hline \multicolumn{2}{|l|}{ Practice experience (years) } \\
\hline$<5$ & $58(29.0)$ \\
\hline$>5$ & $142(71.0)$ \\
\hline \multicolumn{2}{|l|}{ Working hours } \\
\hline$<10$ & $142(71.0)$ \\
\hline$>10$ & $58(29.0)$ \\
\hline \multicolumn{2}{|c|}{ Have assistant in the pharmacy } \\
\hline Yes & $147(73.5)$ \\
\hline No & $53(26.5)$ \\
\hline \multicolumn{2}{|l|}{ Type of drugstore } \\
\hline Independently owned & $34(17.0)$ \\
\hline Chain & $166(83.0)$ \\
\hline \multicolumn{2}{|l|}{ Location } \\
\hline Central & $57(28.5)$ \\
\hline North & $55(27.5)$ \\
\hline South & $43(21.5)$ \\
\hline West & $32(16.0)$ \\
\hline East & $13(6.5)$ \\
\hline \multicolumn{2}{|c|}{ No. of pharmacists in the same shift } \\
\hline$<2$ & $186(93.0)$ \\
\hline$>2$ & $14 \quad(7.0)$ \\
\hline
\end{tabular}

included in the data analysis. The geographic breakdown of regions was northern 55, eastern 13, central 57, southern 43, and western 32 .

Statistical analysis. Microsoft Excel was applied for the general data analysis and were analyzed by using the Statistical Package for Social Sciences, version 23 (IBM SPSS Inc, Chicago, IL, USA). Descriptive data were expressed as frequencies and percentages.

Results. The response rate was $51.3 \%$ since out of 390 distributed questionnaires, 200 were returned for evaluation. Most of the respondents were male $(n=191$, 95.5\%) and were working in a chain pharmacy. The majority of respondents were aged between 25 to 34 years old and had earned a Bachelor of Science $(\mathrm{n}=130,65 \%)$ with more than 5 years of experience in a community pharmacy $(\mathrm{n}=142,71 \%)$. Approximately $70 \%$ of the respondents scheduled in a 10 -hour or shorter shifts where less than 2 pharmacist were working at a time $(\mathrm{n}=186,93 \%)$, but more than $70 \%$ of them had an assistant present in the pharmacy as summarized in Table 1.

The prevalence of self-reported practice roles by community pharmacists while supplying NSAIDs is shown in Table 2. The majority of the pharmacists declare to follow best practices regularly or occasionally in screening risk factors, dealing with adverse effects, as well as checking drug-drug and drug-herb interactions

Table 2 - The prevalence of self-reported practice roles by community pharmacists in supplying non-steroidal anti-inflammatory drugs (NSAIDs).

\begin{tabular}{|c|c|c|c|}
\hline \multirow[t]{2}{*}{ Practice role } & \multicolumn{3}{|c|}{ Number of community pharmacists } \\
\hline & Regularly* $^{*}$ & Occasionally $^{\dagger}$ & Never ${ }^{\ddagger}$ \\
\hline \multicolumn{4}{|l|}{ Screening for risk factor } \\
\hline $\begin{array}{l}\text { For non-selective } \\
\text { NSAID }\end{array}$ & $110(54.8)$ & $60(29.9)$ & $30(15.2)$ \\
\hline $\begin{array}{l}\text { For selective cox- } 2 \\
\text { NSAID }\end{array}$ & $104(51.9)$ & $58(29.1)$ & $38(18.9)$ \\
\hline \multicolumn{4}{|c|}{$\begin{array}{l}\text { Advice to manage and prevent adverse } \\
\text { effects }\end{array}$} \\
\hline $\begin{array}{l}\text { For non-selective } \\
\text { NSAID }\end{array}$ & $105(52.5)$ & $78(39.1)$ & $17(8.4)$ \\
\hline $\begin{array}{l}\text { For selective Cox-2 } \\
\text { NSAID }\end{array}$ & $100(50.1)$ & 77 (38.5) & $23(11.4)$ \\
\hline \multicolumn{4}{|c|}{$\begin{array}{l}\text { Asking about current drug use/herbs/ } \\
\text { supplements }\end{array}$} \\
\hline $\begin{array}{l}\text { For non- selective } \\
\text { NSAID }\end{array}$ & $85(42.5)$ & $90(4.0)$ & $25(12.5)$ \\
\hline $\begin{array}{l}\text { For selective Cox-2 } \\
\text { NSAID }\end{array}$ & $81(40.5)$ & $86(4.0)$ & $33(16.5)$ \\
\hline \multicolumn{4}{|c|}{$\begin{array}{l}\text { Values are presented as number and percentages }(\%) .{ }^{*} \text { providing } \\
\text { practice to all patients, }{ }^{\dagger} \text { providing to some patients, }{ }^{*} \text { not providing to } \\
\text { all patient. } \\
\text { COX-2: cyclooxygenase-2 }\end{array}$} \\
\hline
\end{tabular}


with NSAIDs. More than half of the pharmacists claimed that they screened for risk factors regularly while supplying both selective (54.88) and non-selective (51.9\%) NSAIDs. Similarly, approximately 50\% of the pharmacists pointed out their regularity in adverse effects notify as well as counseling on managing and protecting against side effects of selective NSAIDs in a similar manner to how they discussed non-selective NSAIDs.

The popular side effects for NSAIDs as described by community pharmacists were epigastric pain, nausea, and vomiting (Figure 1). Therefore, Table 3 shows the descriptive data which focused on the most common frequently reported advice provides to reduce side effects from NSAIDs. The most mutual input to prevent GI complications was to use the drug after a meal; $(n=173$, $86.5 \%)$ for non-selective and selective NSAIDs ( $\mathrm{n}=167$, $83.5 \%)$. Almost half of the pharmacists pointed out they regularly guide patients to use gastro-protective agents ( $n=111,55.5 \%$ for non-selective) ( $n=95,47.5 \%$ for selective NSAIDs). In addition, many pharmacists also claimed that they explain when to stop taking NSAIDs $(\mathrm{n}=129,64.5 \%$ for non-selective NSAIDs) ( $\mathrm{n}=120$, $60 \%$ for selective NSAIDs) and when dose reduction may be needed as well $(\mathrm{n}=115,57.5 \%$ for non-selective NSAIDs) ( $\mathrm{n}=111,55.5 \%$ for selective NSAIDs).

The bivariate analysis shown in Table 4 revealed that pharmacists who have an assistant in the pharmacy were significantly more likely to counsel their patients about ADRs related to users of non-selective (odds ratio [OR] $2.966,95 \%$ confidence intervals [CI] 1.462-6.016) and selective COX-2 NSAIDs (OR=2.142, 95\% CI=1.0584.336). In a similar manner, pharmacists with more experience ( $>5$ years) were significantly more likely to
Table 3 - The most reported advices by community pharmacists on prevention against side effects from NSAIDs use.

\begin{tabular}{|c|c|c|c|}
\hline Advice on management & Regularly & Occasionally & Never \\
\hline \multicolumn{4}{|l|}{ For non-selective NSAIDs } \\
\hline Taking NSAIDs after meal & $173(86.5)$ & $24(12.0)$ & $3(1.5)$ \\
\hline Using gastroprotective agent & $111(55.5)$ & $74(37.0)$ & $15(7.5)$ \\
\hline $\begin{array}{l}\text { Switching to another } \\
\text { NSAID class }\end{array}$ & $65(32.5)$ & $115(57.5)$ & $10(10.0)$ \\
\hline $\begin{array}{l}\text { Switching to other } \\
\text { painkillers }\end{array}$ & $83(41.5)$ & $101(50.5)$ & $16(8.0)$ \\
\hline $\begin{array}{l}\text { When to stop taking } \\
\text { NSAID }\end{array}$ & $129(64.5)$ & $66(33.0)$ & $5(2.5)$ \\
\hline $\begin{array}{l}\text { When dose reduction is } \\
\text { needed }\end{array}$ & $115(57.5)$ & $67(33.5)$ & $18 \quad(9.0)$ \\
\hline $\begin{array}{l}\text { What to do with missed } \\
\text { dose }\end{array}$ & $74(37.0)$ & $94(47.0)$ & $32(16.0)$ \\
\hline $\begin{array}{l}\text { When to consult with } \\
\text { physician }\end{array}$ & $110(55.0)$ & $73(36.5)$ & $17 \quad(8.5)$ \\
\hline \multicolumn{4}{|l|}{ For selective NSAIDs } \\
\hline Taking NSAIDs after meal & $167(83.5)$ & $23(11.5)$ & $10 \quad(5.0)$ \\
\hline Using gastroprotective agent & $95(47.5)$ & $75(37.5)$ & $30(15.0)$ \\
\hline $\begin{array}{l}\text { Switching to another } \\
\text { NSAID class }\end{array}$ & $60(30.0)$ & $110(55.0)$ & $30(15.0)$ \\
\hline $\begin{array}{l}\text { Switching to other } \\
\text { painkillers }\end{array}$ & $84(42.0)$ & $95(47.5)$ & $21(10.5)$ \\
\hline $\begin{array}{l}\text { When to stop taking } \\
\text { NSAID }\end{array}$ & $120(60.0)$ & $70(35.0)$ & $10(95.0)$ \\
\hline $\begin{array}{l}\text { When dose reduction is } \\
\text { needed }\end{array}$ & $111(55.5)$ & $69(34.5)$ & $20(10.0)$ \\
\hline $\begin{array}{l}\text { What to do with missed } \\
\text { dose }\end{array}$ & $68(34.0)$ & $93(46.5)$ & $39(19.5)$ \\
\hline $\begin{array}{l}\text { When to consult with } \\
\text { physician }\end{array}$ & $116(58.0)$ & $72(36.0)$ & $12 \quad(6.0)$ \\
\hline
\end{tabular}

Values are presented as numbers and percentages (\%). NSAIDs: non-steroidal anti-inflammatory drugs

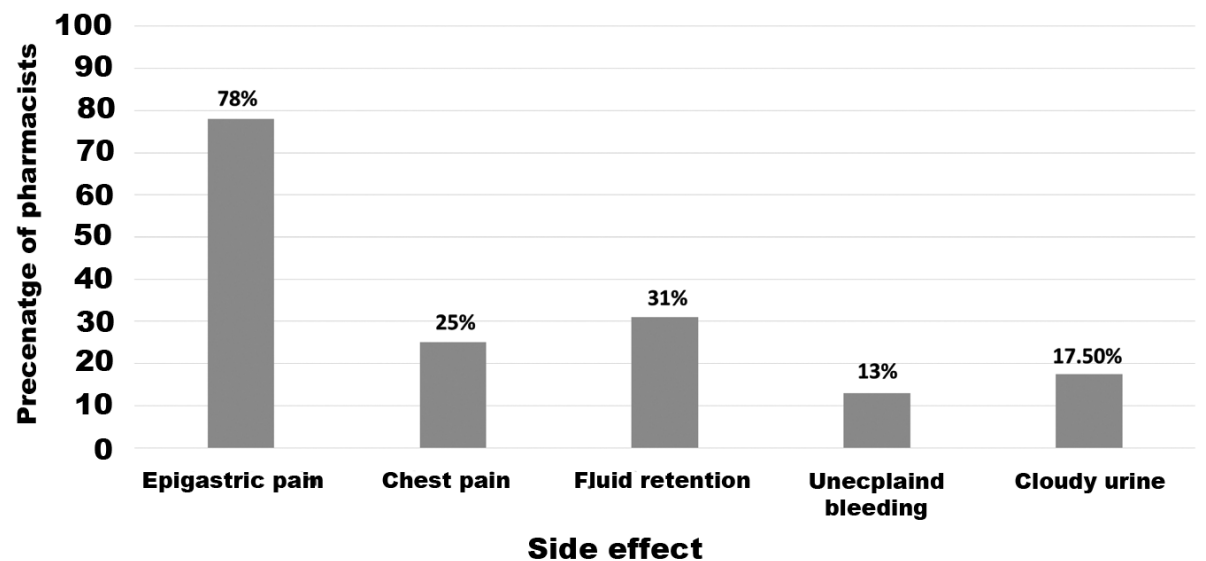

Figure 1 - The major side effects that pharmacists included during NSAIDs: non-steroidal anti-inflammatory drugs counseling. 
Table 4 - Factors related with frequency of side effects information provision to patients of non-selective and selective NSAIDs.

\begin{tabular}{|c|c|c|c|c|c|}
\hline \multirow[t]{2}{*}{ Factors } & \multicolumn{2}{|c|}{ Number of pharmacists } & \multirow{2}{*}{ Odds ratio } & \multirow{2}{*}{$95 \% \mathrm{CI}$} & \multirow{2}{*}{$P$-value } \\
\hline & Regular & Not regular & & & \\
\hline \multicolumn{6}{|l|}{ Non-selective NSAIDs } \\
\hline \multicolumn{6}{|l|}{ Age (years) } \\
\hline$\leq 34$ & $87(65.4)$ & $46(34.6)$ & 1 & - & - \\
\hline$\geq 35$ & $51(76.1)$ & $16(23.9)$ & 1.140 & $0.531-2.448$ & 0.736 \\
\hline \multicolumn{6}{|l|}{ Education } \\
\hline Bachelor of Science or Diploma & $98(69.5)$ & $43(30.5)$ & 1 & - & - \\
\hline $\begin{array}{l}\text { Doctor of Pharmacy + Master of } \\
\text { Science }\end{array}$ & $40(67.8)$ & $19(32.2)$ & 1.152 & $0.529-2.508$ & 0.721 \\
\hline \multicolumn{6}{|l|}{ Type of drug store } \\
\hline Chain & $115(69.3)$ & $51(30.7)$ & 1 & - & - \\
\hline Independently owned & $23(67.6)$ & $11(32.4)$ & 1.154 & $0.478-2.782$ & 0.750 \\
\hline \multicolumn{6}{|l|}{ Have assistant in pharmacy } \\
\hline No & $26(49.1)$ & $27(50.9)$ & 1 & - & - \\
\hline Yes & $112(76.2)$ & $35(23.8)$ & 2.966 & $1.462-6.016$ & $0.003^{\dagger}$ \\
\hline \multicolumn{6}{|l|}{ Pharmacist in same shift } \\
\hline No & $25(54.3)$ & $21(45.7)$ & 1 & - & - \\
\hline Yes & $113(73.4)$ & $41(26.6)$ & 2.009 & $0.923-4.372$ & 0.079 \\
\hline \multicolumn{6}{|l|}{ Experience (yearsO } \\
\hline$\leq 5$ & $32(55.2)$ & $26(44.8)$ & 1 & - & - \\
\hline$>5$ & $106(74.6)$ & $36(25.4)$ & 2.629 & $1.232-5.613$ & $0.012^{*}$ \\
\hline \multicolumn{6}{|l|}{ Selective NSAIDs } \\
\hline \multicolumn{6}{|l|}{ Age (years) } \\
\hline$\leq 34$ & $81(60.9)$ & $52(39.1)$ & 1 & - & - \\
\hline$\geq 35$ & $45(67.2)$ & $22(32.8)$ & 0.821 & $0.393-1.713$ & 0.599 \\
\hline \multicolumn{6}{|l|}{ Education } \\
\hline Bachelor of Science or Diploma & $88(62.4)$ & $53(37.6)$ & 1 & - & - \\
\hline Doctor of Pharmacy + Master of Science & $38(64.4)$ & $21(35.6)$ & 1.159 & $0.543-2.475$ & 0.703 \\
\hline \multicolumn{6}{|l|}{ Type of drug store } \\
\hline Chain & $107(64.5)$ & $59(35.5)$ & 1 & - & - \\
\hline Independently owned & $19(55.9)$ & $15(44.1)$ & 0.827 & $0.356-1.919$ & 0.658 \\
\hline \multicolumn{6}{|l|}{ Have assistant in pharmacy } \\
\hline No & $24(45.3)$ & $29(54.7)$ & 1 & - & - \\
\hline Yes & $102(69.4)$ & $45(30.6)$ & 2.142 & $1.058-4.336$ & $0.034^{*}$ \\
\hline \multicolumn{6}{|l|}{ Pharmacist in same shift } \\
\hline No & $17(37.0)$ & $29(63.0)$ & 1 & - & - \\
\hline Yes & $109(70.8)$ & $45(29.2)$ & 4.330 & $1.980-9.471$ & $<0.0001^{\dagger}$ \\
\hline \multicolumn{6}{|l|}{ Experience (years) } \\
\hline$\leq 5$ & $29(50.0)$ & $29(50.0)$ & 1 & - & - \\
\hline$>5$ & $97(68.3)$ & $45(31.7)$ & 2.788 & $1.303-5.965$ & $0.008^{\dagger}$ \\
\hline
\end{tabular}

counsel their patients about ADRs related to users of non-selective (OR: 2.629, 95\%CI=1.232-5.613) and selective $\quad(\mathrm{OR}=2.788,95 \% \mathrm{CI}=1.303-5.965) \mathrm{COX}-2$ NSAIDs. In addition, having another pharmacist working on the same shift significantly increased (4 times) the likelihood that the pharmacist would inform patients about ADRs linked with selective COX-2 NSAIDs uses (OR 4.330, 95\% CI=1.9809.471). However, there were no statistically significant differences for other factors such as age, education, or type of drug store, which influenced the discussion of ADR linked to non-selective and selective COX-2 NSAIDs users.

Regarding risk factors screening, the majority of the community pharmacists stated that this was performed occasionally when dispensing NSAIDs. The majority of risk factors that pharmacists discussed with patients for non-selective NSAIDs were pregnancy and breastfeeding $(\mathrm{n}=168,84 \%)$ followed by their age $(\mathrm{n}=149,74.5 \%)$ and history of GI ulcers $(\mathrm{n}=143,71.5 \%)$ or bleeding. 
Table 5 - Frequency of non-selective and selective NSAID risk factor screening by community pharmacists.

\begin{tabular}{|c|c|c|c|}
\hline \multirow[t]{2}{*}{ Screening of risk factors } & \multicolumn{3}{|c|}{ No. of community pharmacists (\%) } \\
\hline & Regularly & Occasionally & Never \\
\hline \multicolumn{4}{|l|}{ Non-selective NSAIDs } \\
\hline History of GI ulcer bleeding & $143(71.5)$ & $47(23.5)$ & $10 \quad(5.0)$ \\
\hline Cardiovascular disease & $117(58.0)$ & $61(30.5)$ & $22(11.0)$ \\
\hline Multiple NSAIDs, long term, high dose & $136(68.0)$ & $53(26.5)$ & $11 \quad(5.5)$ \\
\hline History of renal impairment & $118(59.0)$ & $59(29.5)$ & $23(11.5)$ \\
\hline History of liver impairment & $107(53.5)$ & $49(24.5)$ & $44(22.0)$ \\
\hline Older age & $149(74.5)$ & $33(16.5)$ & $18(9.0)$ \\
\hline Allergy & $103(51.5)$ & $66(33.0)$ & $31(15.5)$ \\
\hline Current viral infection & $34(17.0)$ & $94(47)$ & $72(36.0)$ \\
\hline Pregnancy breast feeding & $168(84.0)$ & $26(13.0)$ & $6 \quad(3.0)$ \\
\hline Uncontrolled hypertension & $122(61.0)$ & $59(29.5)$ & $19 \quad(9.5)$ \\
\hline Upcoming surgery procedure & $38(19.0)$ & $83(41.5)$ & $79(39.5)$ \\
\hline Taking steroid drug & $82(41.0)$ & $89(44.5)$ & $29(14.5)$ \\
\hline \multicolumn{4}{|l|}{ Selective NSAIDs } \\
\hline History of GI ulcer/bleeding & $117(58.5)$ & $55(27.5)$ & $28(14.0)$ \\
\hline Cardiovascular disease & $117(58.5)$ & $57(28.5)$ & $26(13.0)$ \\
\hline Multiple NSAIDs long term high dose & $113(56.5)$ & $51(25.5)$ & $36(18.0)$ \\
\hline History of renal impairment & $117(58.5)$ & $50(25.0)$ & $33(16.5)$ \\
\hline History of liver impairment & $104(52.0)$ & $48(24.0)$ & $48(24.0)$ \\
\hline Older age & $138(69.0)$ & $40(20.0)$ & $22(11.0)$ \\
\hline Allergy & $91(45.5)$ & $67(33.5)$ & $42(21.0)$ \\
\hline Current viral infection & $35(17.5)$ & $91(45.5)$ & $74(37.0)$ \\
\hline Pregnancy breast feeding & $161(80.5)$ & $28(14.0)$ & $11 \quad(5.5)$ \\
\hline Uncontrolled hypertension & $120(60.0)$ & $56(28.0)$ & $24(12.0)$ \\
\hline Upcoming surgery procedure & $44(22.0)$ & $79(39.5)$ & $77(38.5)$ \\
\hline Taking steroid drug & $89(44.5)$ & $77(38.5)$ & $34(17.0)$ \\
\hline
\end{tabular}

Values are presented as numbers and percentages (\%). GI: gastrointestinal, NSAIDs: non-steroidal anti-inflammatory drugs

A similar observation regarding the majority of risk factors was found for selective NSAIDs (Table 5).

Discussion. This study in Saudi Arabia to aims to evaluate the awareness and profession by community pharmacists with their patients regarding the use of NSAIDs. In Saudi Arabia, there is an easy access to NSAIDs in the community pharmacies. Thus, it takes a great effort by the pharmacist to ensure appropriate awareness about these drugs before dispensing them. However, patients received limited safety information about appropriate monitoring and preventing side effects regarding their NSAIDs medicines from healthcare providers. ${ }^{17}$

Many studies have been conducted worldwide to evaluate public knowledge and attitude regarding the use of over-the-counter (OTC) medications and particularly NSAIDs. These studies revealed inadequate patient knowledge about side effects which require more advice and consultation regarding appropriate management or prevention tips to mitigate the risks of
NSAIDs. ${ }^{2,13,18-22}$ A study conducted in Jeddah, Saudi Arabia among NSAIDs users found that approximately $75 \%$ of them were not counselled by a healthcare provider on the risks of NSAIDs and more than $90 \%$ of them were united in the opinion that greater efforts are needed from healthcare providers in presenting information regarding ADRs., ${ }^{2,13-21}$ Receiving information about NSAIDs in any way other than from the authorized person may lead to inaccurate and nonspecific information. In addition, the material in the medication leaflets is not suitable for the public. Therefore, only a few patients are able to comprehend the content. Evaluation of medication inserts in Saudi Arabia reports there is a shortage of information in comparison with comparable information in the United States. ${ }^{18,20,23,24}$ Health care providers and pharmacists are a valuable source of accurate information that increases their responsibility and role as medication experts. Pharmacists should be aware of the most risk factors while dispensing NSAIDs and able to screen 
and monitor patients at risks to reduce NSAIDs complications..$^{18,20,23}$

Regardless of the differences in patient responses and preferences, adverse effects caused by NSAIDs use have been observed and more evaluation about patients' knowledge concerning these risks is needed. The most popular adverse effects were GI side effects, which could be aggravated by age, peptic ulcer history, and multiple doses of NSAIDs. Selective NSAIDs superior the traditional NSAIDs in regard to side effects particularly GI tract side effects. Renal, hepatic, cardiovascular, and haematologic side effects have also been commonly reported with the use of NSAIDs. ${ }^{25}$

The majority of community pharmacists claimed to review patient risk factors and provide advice about the management of side effects but others indicated they did not do this for all patients. These results were consistent with a study by Babelghaith et $\mathrm{al}^{13}$ which indicated that more than $30 \%$ of the participants receive insufficient information about possible side effects from NSAIDs. However, our results cannot be generalized as we did not differentiate between the counseling or requested information from patients. Another study about counseling practice conducted in Riyadh, Saudi Arabia showed a 40\% improvement in the rate of counseling due to requested information from the patients. ${ }^{22}$ It is probable that the percentage of pharmacists who delivered best practice in counseling and screening their patients may be overestimated. At the same time, previous research supports the concept that by reporting the current defect in good dispensing practices and medication counseling regarding ADRs will improve the management of adverse effects by community pharmacies in Saudi Arabia. ${ }^{13,23,26,27}$ Interetingly, pharmacists with more experience $(>5$ years) as well as who have an assistant in the pharmacy significantly more likely to inform their patients on ADRs which shows successfulness in improving the quality of drug dispensing. Having more experience gives pharmacists a level of professional confidence and knowledge to be proactive in providing advice to their patients. Also, having an assistant provides more time for pharmacists to interact with patients and provides high quality patient care.

The main risk factors for NSAIDs ADRs as reported were for pregnancy and breast-feeding, older age, and history of GI bleeding. Many studies indicated that patients should be screened for the existence of GI and cardiovascular side effects before using NSAIDs, and should undergo GI-prevention therapy when risk could be an issue. ${ }^{28-31}$ In Europe, the majority of the patient using NSAIDs with one or more risk factors for GI complications received poor prevention treatments. ${ }^{25}$ Using NSAIDs regardless of COX selectivity and duration of use would increase the risk of side effects of cardiovascular and bleeding complications. ${ }^{32}$ Age is considered to be a significant risk factor for NSAIDsrelated GI complications and appropriate management strategies should be applied in the elderly. ${ }^{33}$

Many studies have indicated that selective COX-2 inhibitors cause critical adverse cardiovascular effects including myocardial infarction, cerebrovascular accidents and heart failure. ${ }^{34,35}$ Thus, appropriate knowledge and awareness of the risks of adverse effects could contribute to a patient's decision to take NSAIDS or not. ${ }^{36}$ However, it is a pharmacist's role to improve prescribing practice by striking a balance between providing information to them while at the same time allaying worries that may affect their management plan.

Although this study showed some positive observation from pharmacists regarding good qualities associated with dispensing NSAIDs, it was found that community pharmacies still need to apply good comprehensive services in relation to dispensing these widely used medications that could result in serious ADRs.

During the current COVID-19 epidemic, there is an intense need for the public to be educated and consulted about the proper use of NSAIDs after an alarming finding that suggested a detrimental effect of NSAIDs used in patients with COVID-19. ${ }^{37}$ The FDA responded to those reports and suggested NSAIDs may worsen COVID-19 cases without any clear scientific evidence. ${ }^{38}$ Professional health care providers, especially community pharmacists, should enhance consciousness of NSAIDs risks between consumers, proper counseling and evaluate potential risk factors as well as assort safety notification to assure safe and suitable use of these drugs. ${ }^{13,16,22,39-42}$

Study limitation. This study is using a cross sectional survey of community pharmacist to evaluate the NSAIDs prescribing practice. Simulated patient method could be a robust method for assessing prescribing practice and result in more accurate assessments. ${ }^{22}$

In conclusion, the study highlights the current insufficiencies in medication counseling and proper practices at community pharmacies in Saudi Arabia. Appropriate patient counseling and conscious dispensing of medications are needed to minimize adverse effects associated with self-medication. Community pharmacists in Saudi Arabia need to appropriately screen their patients for the risks of NSAIDs complications and effectively communicate accordingly. The Saudi regulatory authority could 
endorse several approaches to apply a good strategy for improving the dispensing practices in community pharmacies, communication and awareness of risk factors especially in high-risk patients who are taking NSAIDs. Then, intensive research will be required in the coming years to monitor the implementation. More studies are required to evaluate the prevalence of counseling and advice among community pharmacies in other cities in Saudi Arabia. Future studies that apply simulated visits to community pharmacies are also needed to observe the actual counseling practice for robust findings and results.

Acknowledgment. The authors gratefully acknowledge Cambridge (www.cambridgeproofreading.org) for English language editing.

\section{References}

1. Diener H-C, Schneider R, Aicher B. Per-capita consumption of analgesics: a nine-country survey over 20 years. $J$ Headache Pain 2008; 9: 225.

2. Babakor SD, Al Ghamdi MM. Prevalence and Determinants of Over-the-Counter Analgesics Usage among Patients attending Primary Health Care Centers in Jeddah, Saudi Arabia. J Young Pharm 2018; 10: 91-97.

3. AlKhamees OA, AlNemer KA, Maneea MWB, AlSugair FA, AlEnizi BH, Alharf AA. Top 10 most used drugs in the Kingdom of Saudi Arabia 2010-2015. Saudi Pharm J 2018; 26 : 211-216.

4. Al Essa M, Alshehri A, Alzahrani M, Bustami R, Adnan S, Alkeraidees A, et al. Practices, awareness and attitudes toward self-medication of analgesics among health sciences students in Riyadh, Saudi Arabia. Saudi Pharm J 2019; 27: 235-239.

5. Makeen HA, Albarraq AA, Banji OJ, Taymour S, Meraya A, Alqhatani $S$, et al. Knowledge, attitudes, and practices toward self-medication in a rural population in South-Western Saudi Arabia. Saudi J Health Sci 2019; 8: 54-59.

6. Wongrakpanich S, Wongrakpanich A, Melhado K, Rangaswami J. A comprehensive review of non-steroidal anti-inflammatory drug use in the elderly. Aging Dis 2018; 9: 143-150.

7. Food and Drug Administration (FDA). Medication Guide for Non-Steroidal Anti-Inflammatory Drugs (NSAIDs). [Updated 2016. Accessed 2020 January 16]. Available from URL: https:// wwwfdagov/media/72932/download

8. Bidaut-Russell M, Gabriel SE. Adverse gastrointestinal effects of NSAIDs: consequences and costs. Best Pract Res Clin Gastroenterol 2001; 15: 739-753.

9. Howard R, Avery A, Slavenburg S, Royal S, Pipe G, Lucassen P, et al. Which drugs cause preventable admissions to hospital? A systematic review. Br J Clin Pharmacol 2007; 63: 136-147.

10. Rahme E, Joseph L, Kong SX, Watson DJ, LeLorier J. Gastrointestinal health care resource use and costs associated with nonsteroidal antiinflammatory drugs versus acetaminophen: retrospective cohort study of an elderly population. Arthritis \& Rheumatology 2000; 43: 917-924.

11. Davis A, John Robson. The dangers of NSAIDs: look both ways.Br J Gen Pract 2016; 66: 172-173.
12. Almalak H, Albluwi AaI, Alkhelb DA, Alsaleh HM, Khan TM, Hassali MAA, et al. Students' attitude toward use of over the counter medicines during exams in Saudi Arabia. Saudi Pharm J 2014; 22: 107-112.

13. Babelghaith SD, Alarifi MN, Wajid S, Alhawassi TM, Alqahtani SK, Alghadeer SM. Knowledge of patients on safe medication use in relation to nonsteroidal anti-inflammatory drugs. Saudi J Anaesth 2019; 13: 106-111.

14. AlRuthia Y, Alsenaidy MA, Alrabiah HK, AlMuhaisen A, Alshehri M. The status of licensed pharmacy workforce in Saudi Arabia: a 2030 economic vision perspective. Hum Resour Health 2018; 16: 28.

15. Ministry of Health. Statistical Yearbook. (Updated 2018. accessed on 16 April 2019). Available from URL: https:// www.moh.gov.sa/Ministry/Statistics/book/Documents/bookStatistics-2018.pdf

16. Phueanpinit P, Pongwecharak J, Krska J, Jarernsiripornkul N. Evaluation of community pharmacists' roles in screening and communication of risks about non-steroidal anti-inflammatory drugs in Thailand. Prim Health Care Res Dev 2018; 19: 598-604.

17. Jarernsiripornkul N, Phueanpinit P, Pongwecharak J, Krska J. Experiences of and attitudes towards receiving information about non-steroidal anti-inflammatory drugs: a cross-sectional survey of patients in Thailand. Expert Opin Drug Saf 2016; 15: 417-426.

18. Jarernsiripornkul N, Phueanpinit P, Pongwecharak J, Krska J. Development and evaluation of user-tested Thai patient information leaflets for non-steroidal anti-inflammatory drugs: Effect on patients' knowledge. PloS One 2019; 14:e0210395.

19. Karami NA, Altebainawi AF, Alfarki SA, Aldossari NB, Asiri AN, Aldahan MS, et al. Knowledge and attitude of analgesics use among Saudi population: A cross-sectional study. Int J Med Sci Public Health 2018; 7: 137-143.

20. Abougalambou SS, Abdoun SA, SayerAlharbi N. Awareness of non-steroidal anti-inflammatory drugs (NSAIDs) use among population in Saudi Arabia. Open J Pharm Sci Res 2019: 1: 40-45.

21. Bahdailah A. Basic knowledge of non-steroidal antiinflammatory drugs among saudi community. PTb Reports 2019; 5: 93-96.

22. Jarernsiripornkul N, Phueanpinit P, Pongwecharak J, Krska J. Practices of healthcare professionals in communicating with nonsteroidal anti-inflammatory drug users in Thailand: a qualitative study. Int J Pharm Pract 2019: 27: 326-369.

23. Alaqeel S, Abanmy NO. Counseling practices in community pharmacies in Riyadh, Saudi Arabia: a cross-sectional study. BMC Health Serv Res 2015; 15: 557.

24. Al-Aqeel SA. Evaluation of medication package inserts in Saudi Arabia. Drug Healthc Patient Saf 2012; 4: 33-38.

25. Chua SS, Paraidathathu T. Utilisation of non-steroidal antiinflammatory drugs (NSAIDs) through community pharmacies in Malaysia. Asia Pac J Public Health 2005; 17: 117-123.

26. Puspitasari HP, Aslani P, Krass I. A review of counseling practices on prescription medicines in community pharmacies. Research in social \& administrative pharmacy. Res Social Adm Pharm 2009; 5: 197-210. 
27. Al-Mohamadi A, Badr A, Bin Mahfouz L, Samargandi D, Al Ahdal A. Dispensing medications without prescription at Saudi community pharmacy: extent and perception. Saudi Pharm J 2013; 21: 13-18.

28. Lanas A, Esplugues J-V, Zapardiel J, Sobreviela E. Educationbased approach to addressing non-evidence-based practice in preventing NSAID-associated gastrointestinal complications. World J Gastroenterol 2009;15: 5953-5939.

29. Park K, Bavry AA. Risk of stroke associated with nonsteroidal anti-inflammatory drugs. Vasc Health Risk Manag 2014; 10 : 25-32.

30. Layton D, Souverein PC, Heerdink ER, Shakir SA, Egberts AC. Evaluation of risk profiles for gastrointestinal and cardiovascular adverse effects in nonselective NSAID and COX-2 inhibitor users: a cohort study using pharmacy dispensing data in The Netherlands. Drug Saf 2008; 31: 143-158.

31. Han MH, Nam JH, Noh E, Lee EK. Gastrointestinal risk of non-steroidal anti-inflammatory drugs and gastroprotective agents used in the treatment of osteoarthritis in elderly patients: a nationwide retrospective cohort study. Int J Clin Pharmacol Ther 2019; 57: 531-541.

32. Ross SJ, Elgendy IY, Bavry AA. Cardiovascular safety and bleeding risk associated with nonsteroidal anti-inflammatory medications in patients with cardiovascular disease. Curr Cardiol Rep 2017; 19: 8.

33. Lanas A, Ferrandez A. Inappropriate prevention of NSAIDinduced gastrointestinal events among long-term users in the elderly. Drugs Aging 2007; 24: 121-131.

34. Batlouni $M$. Nonsteroidal anti-inflammatory drugs: cardiovascular, cerebrovascular and renal effects. Arq Bras Cardiol 2010; 94: 556-563.
35. Khan S, Andrews KL, Chin-Dusting JPF. Cyclo-oxygenase (cox) inhibitors and cardiovascular risk: are non-steroidal antiinflammatory drugs really anti-inflammatory? Int J Mol Sci 2019; 20: 4262.

36. Carrigan N, Raynor D, Knapp P. Adequacy of patient information on adverse effects. Drug Saf 2008; 31: 305-312.

37. Russell B, Moss C, Rigg A, Van Hemelrijck M. COVID-19 and treatment with NSAIDs and corticosteroids: should we be limiting their use in the clinical setting? Ecancermedicalscience 2020; 14: 1023.

38. U.S Food and Drug Administration. FDA advises patients on use of non-steroidal anti-inflammatory drugs (NSAIDs) for COVID-19. [Updated 2020 February 13. Accessed 2020 April 20].Available from URL: https://www.fda.gov/drugs/drugsafety-and-availability/fda-advises-patients-use-non-steroidalanti-inflammatory-drugs-nsaids-covid-19

39. Al Laif FZ, Ahmad R, Naqvi AA, Ahmad N. Pharmacist perceived barriers to patient counseling; a study in eastern region of Saudi Arabia. J Pharm Res Int 2017; 19: 1-12.

40. Asrade SA, Mishra B. Assessment of dispensing practice and associated factors towards patient medication counseling in dessie town, north east ethiopia. Biotechnol Res Int 2016; 9: 111-121

41. Halila GC, Junior EH, Otuki MF, Correr CJ. The practice of OTC counseling by community pharmacists in Parana, Brazil. Pharma Prac 2015; 13: 597.

42. Tarn DM, Wenger A, Good JS, Hoffing M, Scherger JE, Wenger NS. Do physicians communicate the adverse effects of medications that older patients want to hear? Drugs Ther Perspect 2015; 3: 68-76. 